\title{
Adipose tissue supports normalization of macrophage and liver lipid handling in obesity reversal
}

\author{
Maayan Vatarescu1,2,*, Sapir Bechor1,2,*, Yulia Haim,2, Tal Pecht1,2, Tanya Tarnovscki1, \\ Noa Slutsky', Ori Nov', Hagit Shapiro', Avishai Shemesh ${ }^{3}$, Angel Porgador ${ }^{3}$, \\ Nava Bashan' and Assaf Rudich ${ }^{1,2}$ \\ ${ }^{1}$ The Department of Clinical Biochemistry and Pharmacology, Faculty of Health Sciences, Ben-Gurion \\ University of the Negev, Beer-Sheva, Israel \\ 2The National Institute of Biotechnology in the Negev (NIBN), Ben-Gurion University, Beer-Sheva, Israel \\ ${ }^{3}$ The Shraga Segal Department of Microbiology, Immunology and Genetics, Ben-Gurion University, \\ Beer-Sheva, Israel \\ *(M Vatarescu and S Bechor contributed equally to this work)
}

Correspondence should be addressed to A Rudich Email rudich@bgu.ac.il

\begin{abstract}
Adipose tissue inflammation and dysfunction are considered central in the pathogenesis of obesity-related dysmetabolism, but their role in the rapid metabolic recovery upon obesity reversal is less well defined. We hypothesized that changes in adipose tissue endocrine and paracrine mechanisms may support the rapid improvement of obesityinduced impairment in cellular lipid handling. C57BI-6J mice were fed ad libitum either normal chow (NC) or high-fat diet (HFF) for 10 weeks. A dietary obesity reversal group was fed HFF for 8 weeks and then switched to NC for 2 weeks (HFF $\rightarrow N C$ ). Whole-body glucose homeostasis rapidly nearly normalized in the HFF $\rightarrow$ NC mice (fasting glucose and insulin fully normalized, glucose and insulin tolerance tests reversed $82 \%$ to the NC group levels). During 2 weeks of the dietary reversal, the liver was significantly cleared from ectopic fat, and functionally, glucose production from pyruvate, alanine or fructose was normalized. In contrast, adipose tissue inflammation (macrophage infiltration and polarization) largely remained as in HFF, though obesity-induced adipose tissue macrophage lipid accumulation decreased by $\sim 50 \%$, and adipose tissue MAP kinase hyperactivation was reversed. Ex vivo, mild changes in adipose tissue adipocytokine secretion profile were noted. These corresponded to partial or full reversal of the excess cellular lipid droplet accumulation induced by HFF adipose tissue conditioned media in hepatoma or macrophage cells, respectively. We propose that early after initiating reversal of nutritional obesity, rapid metabolic normalization largely precedes resolution of adipose tissue inflammation. Nevertheless, we demonstrate a hitherto unrecognized contribution of adipose tissue to the rapid improvement in lipid handling by the liver and by macrophages.
\end{abstract}

\section{Key Words}

- adipose tissue macrophages

- obesity reversal

- adipose tissue inflammation

- glucose production

- insulin resistance
Journal of Endocrinology (2017) 233, 293-305 Printed in Great Britain

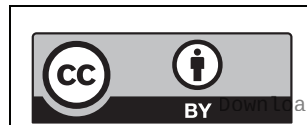

This work is licensed under a Creative Commons Attribution 3.0 Unported License. 


\section{Introduction}

Adipose tissue inflammation is frequently viewed as a central mechanism in the pathogenesis of obesityassociated glucose intolerance and metabolic dysregulation. In humans, association studies demonstrated that adipose tissue inflammation (particularly macrophage infiltration) characterizes obese persons who develop insulin resistance (Harman-Boehm et al. 2007), but to a much lesser degree age, sex and BMI-matched obese persons who remain insulin sensitive (Kloting et al. 2010). In mouse models amenable to detailed time-course analyses, even shortterm (3 days) high-fat feeding (HFF) induced neutrophildominated adipose tissue inflammation. This inflammatory response clearly occurred before the development of obesity (Elgazar-Carmon et al. 2008, Talukdar et al. 2012), but already could be tied to insulin resistance, particularly in the liver (Elgazar-Carmon et al. 2008, Hadad et al. 2013).

The secretory profile of adipose tissue is thought to be altered by adipose tissue inflammation and mediate its impact on whole-body metabolic state. Auto-paracrine communication affects the function of cells within adipose tissue, and distant tissues (muscle, brain and pancreas) are endocrine targets of secreted products from adipose tissues. Indeed, the particularly strong association of visceral adiposity with insulin resistance, glucose intolerance and dyslipidemia could also implicate adipose tissue inflammation, as visceral fat exhibits higher inflammatory markers compared to subcutaneous fat (Harman-Boehm et al. 2007, Item \& Konrad 2012). Moreover, the direct communication of visceral fat with the liver via the portal vein implicates the liver as a central target for the endocrine dysfunction caused by visceral fat inflammation (Rytka et al. 2011, Item $\&$ Konrad 2012). Consistently, various means of interfering with obesity-related adipose tissue changes, including inhibition of inflammatory cascades and the stress-related MAP kinase JNK, resulted in decreased hepatic steatosis, insulin resistance and glucose overproduction (Sabio et al. 2008, Wueest et al. 2010, Zhang et al. 2011).

Compared to this wealth of studies implicating adipose tissue inflammation in the pathogenesis of obesity-related metabolic dysfunction, much less is known about its role in the resolution of glucose intolerance and impaired lipid handling upon caloric restriction and/or obesity reversal. A striking, and poorly explained observation, in both humans and experimental models, has been that dysglycemia can be very rapidly normalized after bariatric surgery (Varela 2011, Bradley et al. 2012). Changes in incretins, bile acids, possibly engaging the microbiota, have been raised as possible mechanisms (Cho 2014). Clearly, resolution of obesity itself is not required for this metabolic improvement, which in some patients even results in remission of preoperative overt type 2 diabetes. Moreover, when inducing weight loss in HFF mice, dysglycemia improved without apparent resolution of adipose tissue inflammation (Jung et al. 2013), and lipid droplets in adipose tissue macrophages (ATM) were even increased early in the course of caloric restriction (Kosteli et al. 2010). Yet, reversal of obesity-associated liver changes (steatosis) may be better aligned with metabolic normalization (Fabbrini et al. 2009). Thus, it remains largely unknown whether resolution of obesity-associated glucose and lipid dysmetabolism is largely independent of adipose tissue or whether normalization of the paracrine/endocrine function of adipose tissue remains a contributing factor, despite grossly retained adipose tissue inflammation.

Here, we challenged the hypothesis that early in the course of reversal of diet-induced obesity, adipose tissue's paracrine and endocrine function contributes to metabolic normalization, in particular, of lipid handling within adipose tissue and by hepatocytes. Furthermore, we assessed whether these functions associate with the reversal of obesity-induced adipose tissue inflammation, stress response and increased ATM lipid content.

\section{Methods}

\section{Reagents}

Tissue culture medium, serum and antibiotic solutions were obtained from Biological Industries (Beit-HaEmek, Israel). Recombinant human insulin was from Novo Nordisk. Source and catalogue numbers for all antibodies and PCR primers are presented in Supplementary Table 1 (see section on supplementary data given at the end of this article).

\section{Animals and treatments}

The study was approved in advance by Ben-Gurion University Institutional Animal Care and Use Committee and was conducted according to the Israeli Animal Welfare Act following the guidelines of the Guide for Care and Use of Laboratory Animals (National Research Council 1996). Six-week-old male C57BL/6J mice (Harlan Laboratories, Rehovot, Israel) were acclimatized for 2 weeks, housed 2-4/cage in a monitored animal facility with 12:12 light:darkness

Published by Bioscientifica Ltd. 
cycle. Mice had free access to filtered water and standard rodent chow (11\% calories from fat, $65 \%$ from carbohydrates and $24 \%$ from protein; Altromin, Lage, Germany). At the age of 8 weeks, mice were randomly divided into 3 groups for a 10-week dietary intervention: (i) normal chow (NC, as detailed previously); (ii) highfat diet (HFF, 58.7\% calories derived from fat, 25.5\% carbohydrate and $15 \%$ protein, D12492; Research Diets, New Brunswick, NJ); (iii) reversibility group $(\mathrm{HFF} \rightarrow \mathrm{NC})$ was given HFF for 8 weeks followed by 2 additional weeks of NC (all ad libitum). The two-week time point was chosen to serve our hypothesis focusing on early liver and adipose tissue changes at a time with significant but incomplete body weight reversal, but a near-complete normalization of glycemic control. Mice were weighed weekly at the same hour. For insulin signaling, in vivo insulin was injected after overnight fast $12 \mathrm{~min}$ before the mice were killed with $\mathrm{CO}_{2}$ or isoflurane. Tissue lysates were prepared in RIPA lysis buffer from $15 \mathrm{mg}$ liver or $100 \mathrm{mg}$ epididymal adipose tissue, as previously detailed (Nov et al. 2013). When not displayed in the graph, number of mice/group for each analysis is mentioned in the legends and was always derived from 2 to 4 independent experiments.

\section{Insulin and HOMA-IR measurements}

Glucose was measured using a glucometer (Abbott). Insulin was measured in serum by an ultra-sensitive ELISA kit (Crystal Chem Inc., Downers Grove, IL, USA, catalogue \#90800). HOMA-IR (homeostatic model assessmentinsulin resistance) was calculated as fasting glucose $(\mathrm{mg} /$ $\mathrm{dL}) \times$ fasting insulin $(\mathrm{mIU} / \mathrm{L}) / 405$.

\section{Glucose, insulin, pyruvate, alanine and fructose tolerance tests}

Mice were fasted for $4 \mathrm{~h}$ for the insulin tolerance test (ITT, 0.2 Uinsulin $/ \mathrm{kg}$ body weight), and overnight for all other loading tests (glucose, alanine, pyruvate or fructose, all at $2 \mathrm{~g} / \mathrm{kg}$ ). Blood was drawn from the tail at the indicated time points. Area under the glucose excursion curve (AUC) was calculated by GraphPad software (Prism 5).

\section{Histology}

Dissected liver and adipose tissue were fixed in $4 \%(\mathrm{v} / \mathrm{v})$ paraformaldehyde at $4^{\circ} \mathrm{C}$, processed and embedded in (c) 2017 The authors Printed in Great Britain paraffin. Sections of $5 \mu \mathrm{m}$ were stained with hematoxylin and eosin (H\&E). Images were taken using an Olympus BX60 microscope. The percentage of liver histological sections area containing lipid-laden heptaocytes was estimated in 4 different X20 fields, 4 mice per group, from H\&E-stained sections using an in-house MATLAB-based software. Adipocyte cell-size distribution was assessed as we previously reported (Nov et al. 2013).

\section{FACS analysis of adipose tissue stromal-vascular fraction (SVF)}

It was performed after collagenase digestion and an additional wash with $10 \mathrm{mM}$ EDTA to ensure the separation of lipid-laden macrophages, as we previously described (Nov et al. 2013, Shapiro et al. 2013). After FcBlock (BD Biosciences, Franklin Lakes, NJ, USA), cells were stained with the following conjugated antibodies $(10 \mathrm{~min}$ on ice in the darkness): CD45-APC, F4/80-PE-Cy7 (both from E-Bioscience, San Diego, CA, USA) and CD11b-APC-Cy7 (BD Pharmingen, San Diego, CA, USA). Cells were washed and pellets were then stained for $20 \mathrm{~min}$ on ice with BODIPY 493/503 ( $3 \mu \mathrm{g} / \mathrm{mL}$ BODIPY for $5 \times 10^{6}$ cells; Invitrogen, D3922). Stained samples were further washed and filtered using $100 \mu \mathrm{m}$ mesh. Propidium iodide $(0.2 \mu \mathrm{g} /$ $\mathrm{mL}$; Sigma, P4864) was added to all samples. Stained samples were analyzed by FACS (Canto, BD Biosciences).

\section{Tissue culture}

Hepa-1c mouse hepatoma cells and RAW264.7 mouse macrophage cell line (American Type Culture Collection, Manassas, VA, USA), were maintained in Dulbecco's Modified Eagle Medium (DMEM), $4.5 \mathrm{~g} / \mathrm{L}$ glucose containing $10 \%(\mathrm{v} / \mathrm{v}) \mathrm{FBS}, 50 \mathrm{U} / \mathrm{mL}$ penicillin, $50 \mu \mathrm{g} / \mathrm{mL}$ streptomycin and $4 \mathrm{mM}$ glutamine (Biological Industries Ltd). For co-culture experiments, Hepa-1c cells were grown to $90 \%$ confluence. Lipid acumulation assays in $3 \times 10^{4}$ Hepa- 1 c cells/well and $2.5 \times 10^{4}$ RAW264.7 cells/ well were plated in 96-well uClear, black plates (Greiner Bio One, Kremsmünster, Austria). All cells were at passage number below 20.

\section{Co-culture and conditioned media preparation}

Epididymal fat pads from NC, HFF or $\mathrm{HFF} \rightarrow \mathrm{NC}$ were minced into $2-3 \mathrm{~mm}^{3}$ fragments $(100 \pm 5 \mathrm{mg} / \mathrm{mL})$ and incubated in full medium for $24 \mathrm{~h}$ for relaxation, as we previously described (Nov et al. 2013, Slutsky et al. 2016).

Published by Bioscientifica Ltd http://joe.endocrinology-journals.org DOI: 10.1530/JOE-17-0007 
The pads were washed with sterile phosphate-buffered saline, and then either co-cultured with Hepa-1c cells for additional $24 \mathrm{~h}$ (100 mg tissue/well) or incubated in fresh medium that was collected (conditioned media, CM). Some HFF fat pads were treated after 2-h relaxation period with $20 \mu \mathrm{M}$ SP600125 (JNK inhibitor) and $20 \mu \mathrm{M}$ SB203580 (p38 inhibitor, both from Sigma-Aldrich) for $24 \mathrm{~h}$ in full serum medium (Supplementary Figure 1, see section on supplementary data given at the end of this article). The pads were washed thoroughly with sterile PBS and co-cultured with Hepa-1c cells for additional $24 \mathrm{~h}$. At the end of the co-culture/conditioned media period, Hepa-1c cells were rinsed and serum starved (DMEM $+0.5 \%$ $(\mathrm{w} / \mathrm{v}) \mathrm{BSA})$ for $3 \mathrm{~h}$, after which explants and media were removed, cells were rinsed and stimulated with $100 \mathrm{nM}$ insulin for $7 \mathrm{~min}$. Cells were then rinsed twice with ice cold sterile PBS and then frozen at $-80^{\circ} \mathrm{C}$ until further analysis by Western blot, as we previously described (Slutsky et al. 2016).

\section{Lipid accumulation}

Hepa-1c and RAW264.7 cells were treated for $6 \mathrm{~h}$ with AT-CM $(20 \%$ or $50 \%(\mathrm{v} / \mathrm{v})$, respectively, diluted in DMEM). BODIPY and Hoechst 33342 (Invitrogen) were added (to a final concentration of $0.2 \mu \mathrm{g} / \mathrm{mL}$ and $1 \mu \mathrm{g} / \mathrm{mL}$, respectively), and cells were imaged in a fully automated and unbiased manner using $\mathrm{X} 40$ wide-angle lens-equipped microscope (Operetta, PerkinElmer) $\left(37^{\circ} \mathrm{C}, 5 \% \mathrm{CO}_{2}\right)$. The number of lipid droplets per cell was calculated by the image analysis software Columbus (Perkin Elmer). Each condition was examined in triplicate, and at least 27 fields per well were captured for statistical analysis.

\section{RNA extraction and quantitative RT-PCR}

Total RNA from fat pads was extracted with the RNeasy lipid tissue mini kit (Qiagen) and analyzed with a NanoDrop. RNA (200ng) were reverse transcribed with High Capacity cDNA Reverse Transcriptase Kit (Applied Biosystems). We used TaqMan system probes (Applied Biosystems) for real-time PCR amplification. Relative gene expression was obtained after normalization to RplpO (36b4) and Hprt using the formula $2^{-\Delta \Delta C T}$.

\section{Adipokine array}

To screen for putative AT-derived mediators, we used an antibody-based protein array (Proteome Profiler: Mouse adipokine array, R\&D Systems, ARRY013) according to the manufacturer's instructions (Slutsky et al. 2016). Quantification was performed using a transmissionmode scanner and image analysis software. Average signal of pixel density from duplicate spots/adipokine was determined using GelQuant NET software (Ver. 1.7.8, University of California, San Francisco, USA). The relative intensity of the reference values (three inside control duplicates in each membrane) was included in the densitometry calculations.

\section{Lipolysis assay}

Adipose tissue CM (100 mg tissue/mL) from the 3 groups was used for free fatty acids (FFA) measurement (NEFA-HR kit, Wako Diagnostics), according to the manufacturer's instructions.

\section{Statistical analysis}

Data are expressed as the mean \pm S.E.M., and calculations were performed using GraphPad Software (Ver. Prism 5 and Prism 6). Percent reversibility of all parameters was calculated as $(\mathrm{HFF}-(\mathrm{HFF} \rightarrow \mathrm{NC})) /(\mathrm{HFF}-\mathrm{NC}) \times 100$. Unless otherwise stated, statistically significant differences between 2 groups were evaluated using the Student's $t$ test, whereas 3 or more groups were assessed by ANOVA followed by Tukey post hoc analysis for the between-group comparison.

\section{Results}

To determine the early dynamics of recovery from obesityassociated metabolic dysfunction, we utilized the highfat-fed (HFF) mouse model. All mice were fed ad libitum, either a normal chow (NC) diet, or HFF, for 10 weeks. The dietary reversal group was switched back to NC after 8 weeks on HFF and followed for the subsequent two weeks $(\mathrm{HFF} \rightarrow \mathrm{NC})$. Within two weeks of the dietary reversal, mice lost $\sim 60 \%$ of their excess total body and epididymal fat mass ('excess' being the difference between the HFF and the NC groups, Fig. 1A and B). Strikingly, fasting glucose levels normalized to the NC group levels 3 days after the dietary switch (Fig. 1C), and by the end of one-week follow-up, fasting-state insulin resistance, as determined by the HOMA-IR index, was fully reversed (Fig. 1D). Using dynamic testing of glucose and insulin tolerance demonstrated that within a week, $\mathrm{HFF} \rightarrow \mathrm{NC}$ mice were http://joe.endocrinology-journals.org DOI: 10.1530/JOE-17-0007
() 2017 The authors Printed in Great Britain
Published by Bioscientifica Ltd 


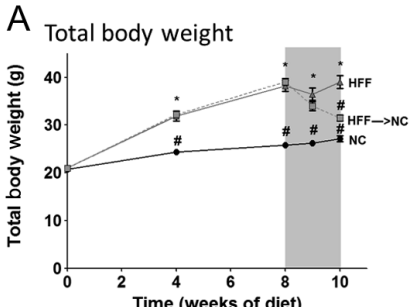

C Fasting glucose

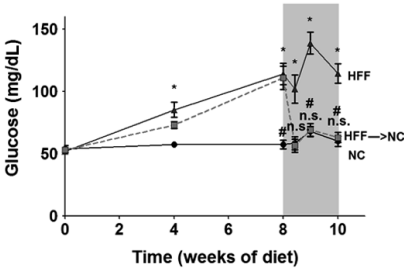

B Epidydimal fat pads weight

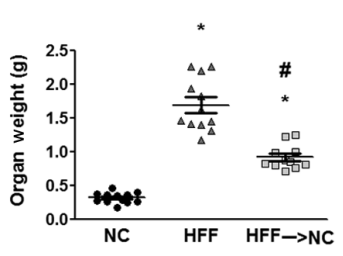

$\mathrm{D}$

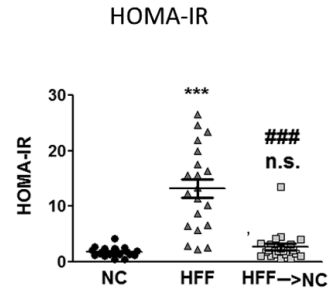

E GTT and $\mathrm{AUC}_{\mathrm{GTT}}$
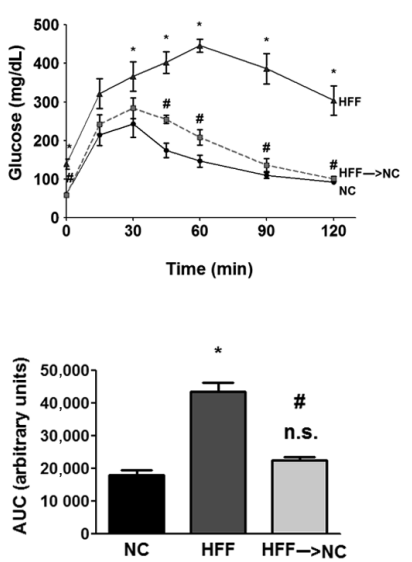

F ITT and $A U C_{I T T}$
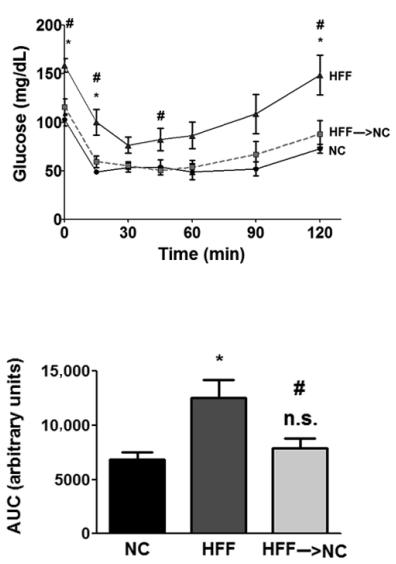

Figure 1

Glucose homeostasis and insulin sensitivity upon dietary switch. Eight-week-old C57BL6 mice were fed normal-chow diet (NC, 10\% kcal from fat) for 10 weeks, high-fat feeding (HFF, $60 \%$ kcal from fat) for 10 weeks or HFF for 8 weeks and then switched to NC for 2 weeks ('reverse group', HFF $\rightarrow$ NC). Total body weight (BW) dynamics (A), epididymal fat at 10 weeks (B), circulating fasting blood glucose (C) and the glucose-to-insulin ratio (homeostatic model of insulin resistance - HOMA-IR) index 7 days after dietary reversal (D) are shown. $n=16-21$ per group. Dynamically, intra-peritoneal glucose tolerance test (i.p. GTT, E) and intra-peritoneal insulin tolerance test (i.p. ITT, F) were performed 7 days after the dietary switch by i.p. administration of $2 \mathrm{~g} / \mathrm{kg} \mathrm{BW}$ glucose after an overnight fast or $0.2 \mathrm{U} / \mathrm{kg} \mathrm{BW}$ insulin after $4-\mathrm{h}$ fast, respectively. Area under the curves (AUC) of the GTT and ITT were

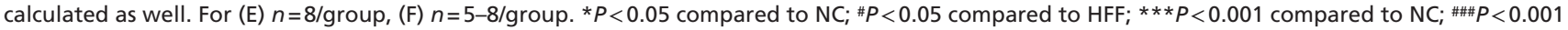
compared to HFF; n.s. - non-significant $(P>0.05)$ compared to NC.

statistically indistinguishable from the NC control group in their glucose values in most time points (Fig. 1E and F). The area under the glucose tolerance test (GTT) or the insulin tolerance test (ITT) curves revealed $82 \%$ reversal of the difference between the obese HFF and the lean control, NC mice. Additional serum biochemical parameters of the mice are presented in Supplementary Table 2. Jointly, results demonstrate a rapid, nearly complete, reversal of insulin resistance and glucose intolerance induced by nutritional obesity upon switching back from obesogenic to normal diet.

Largely consistent with the robust reversal of HFFinduced changes within 2 weeks of dietary switch were the liver findings. Ten weeks of HFF resulted in significant excess liver weight, histologically explained by marked steatosis and hepatocyte ballooning (Fig. 2A, B, C and $D)$. Liver weights of the $\mathrm{HFF} \rightarrow \mathrm{NC}$ group were identical to the NC group, and histologically, a marked reversal of hepatic steatosis was observed. mRNA levels of either the rate-limiting enzyme of de-novo lipogenesis (acetyl CoA carboxylase, Acaca) or of cholesterol biosynthesis (HMG-CoA reductase, Hmgcr) and the lipogenic transcription factor PPAR $\gamma$ (Pparg), increased in HFF mice compared to those of NC (Fig. 2E). The effect of HFF on Pparg expression was completely abrogated in the $\mathrm{HFF} \rightarrow \mathrm{NC}$ group.
Hepatic steatosis is tightly associated with enhanced glucose production, contributing to dysglycemia. To determine the functional impact of the rapid loss in liver fat and its contribution to the near-normalization of whole-body glycemia, we assessed whole-body glucose production by loading tests with different gluconeogenic substrates. HFF mice exhibited significant glucose overproduction from pyruvate, fructose or alanine, compared to NC mice (Fig. 2F, G and H). The glucose excursion curves in the $\mathrm{HFF} \rightarrow \mathrm{NC}$ group were mostly indistinguishable from the NC control group for all three substrates, and the area under the curves showed a tendency for glucose production to be 'over normalized' when pyruvate or alanine were used as gluconeogenic substrates (Fig. 2F, G and H, insets). We did not detect significant changes in gluconeogenic enzymes' mRNA levels, though glucose-6-phosphatase (G6pc) mRNA tended to be $\sim 30 \%$ lower in $\mathrm{HFF} \rightarrow \mathrm{NC}$ mice compared to HFF mice (data not shown). Interestingly, hepatic insulin signaling responsiveness, as assessed by acutely administering a supraphysiological insulin bolus and measuring insulin-stimulated phosphorylation events by Western blotting, demonstrated insulin resistance in the HFF compared to the NC mice' livers. Yet, this hepatic signaling defect was not reversed in the $\mathrm{HFF} \rightarrow \mathrm{NC}$ group (Fig. 2I). Collectively, the rapid normalization of glucose

Published by Bioscientifica Ltd 
A
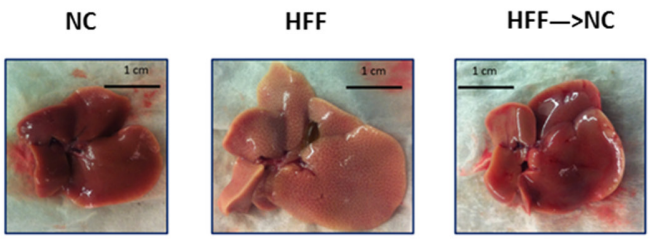

C NC

HFF

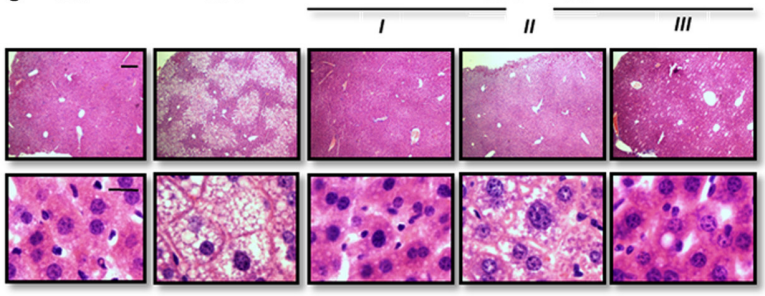

B Liver weight

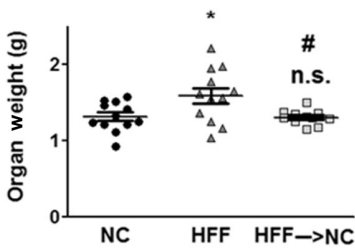

D steatosis area

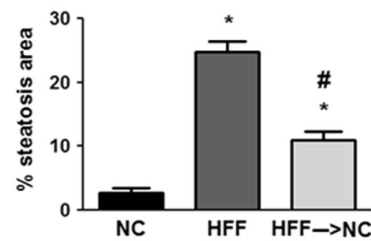

E Lipid metabolism genes

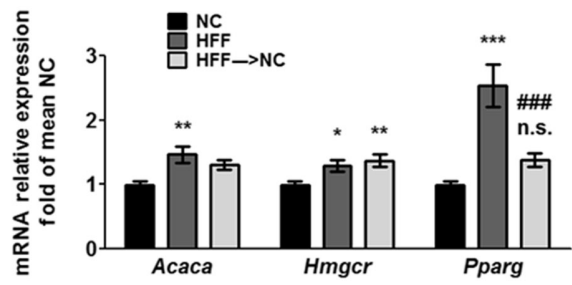

$G$ Fructose tolerance tests and $A U C_{F T}$

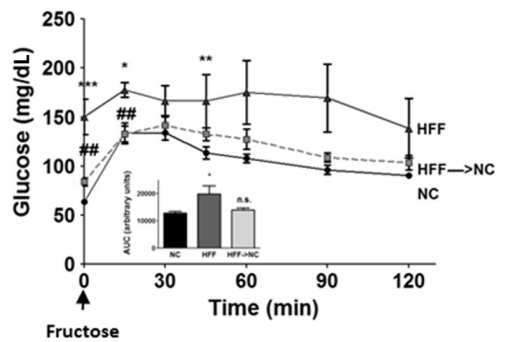

$F$ Pyruvate tolerance tests and $A U C_{P T}$

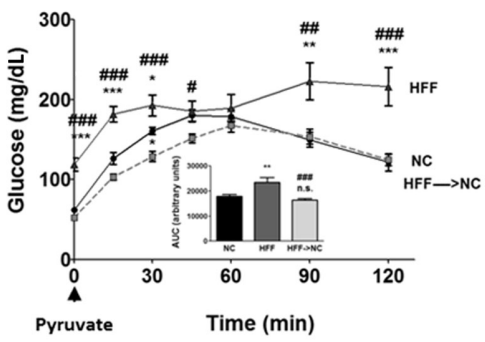

$\mathrm{H}$ Alanine tolerance tests and $\mathrm{AUC}_{\mathrm{AT}}$

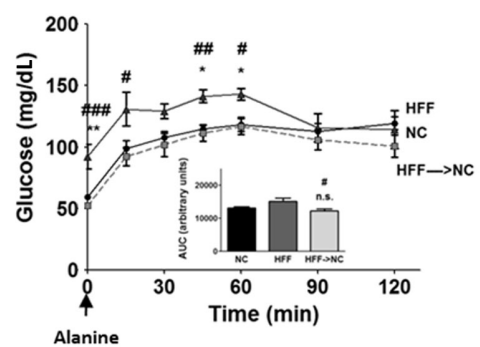

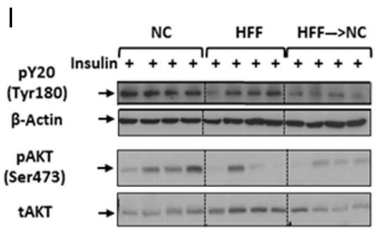

J
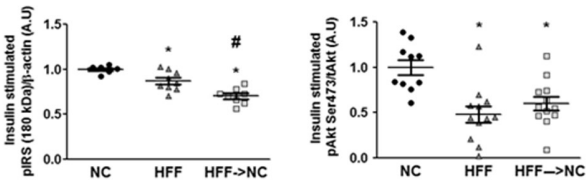

Figure 2

Early hepatic response to obesity reversal. Representative images (A) and weights (B) of livers 14 days after dietary switch ( $n=11-12 /$ group). (C) Representative liver hematoxylin and eosin (H\&E)-stained histological sections of the three groups. I, II and III are sections from 3 individual mice from the $\mathrm{HFF} \rightarrow \mathrm{NC}$ group, demonstrating the variability in this group. (D) Mean area identified as steatotic ( $n=4$ for NC, HFF and $n=8$ for HFF $\rightarrow$ NC. (E) Quantitative real-time PCR of liver expression of lipid metabolism genes: acetyl CoA carboxylase1 (Acaca), HNG CoA reductase (Hmgcr) and peroxisome proliferatoractivated receptor $\gamma$ (PPAR ). Values are the $\triangle \Delta C T$ values adjusted to Rplp0 and Hprt and are presented as fold of mean NC values ( $n=15-16 / g r o u p$, from 4 independent experiments). (F, G and H) Results of pyruvate, fructose and alanine tolerance tests (PTT, FTT and ATT, respectively): twelve days after dietary reversal, mice were injected intraperitoneally with $2 \mathrm{~g} / \mathrm{kg} \mathrm{BW}$ each of the respective metabolites after an overnight fast. Glucose excursions during the following $2 \mathrm{~h}$ are shown. Insets are graphs of the calculated area under the curve (AUC). $n=9-10 /$ group for PTT, $n=5-6 /$ group for FTT and ATT). (I and J) Representative blots and densitometry of insulin signaling molecules in the liver. Mice were fasted overnight, and killed 12 min after intraperitoneal injection of $0.2 \mathrm{U} / \mathrm{kg}$ insulin. $n=7-12 /$ group, from 2 to 3 independent experiments. ${ }^{*} P<0.05$ compared to NC; ${ }^{2} P<0.05$ compared to HFF; $* *$ or $\# \#<0.01$ compared to NC or HFF, respectively; *** or $\# \# P<0.001$ compared to NC or HFF, respectively; n.s. - non-significant $(P>0.05)$ compared to NC.

http://joe.endocrinology-journals.org DOI: $10.1530 / \mathrm{JOE}-17-0007$ (c) 2017 The authors Printed in Great Britain
Published by Bioscientifica Ltd. 
tolerance and insulin sensitivity upon dietary switch was largely matched by robust reversal of liver steatosis and whole-body glucose overproduction, though not of the impaired hepatic insulin signaling hyporesponsiveness.

Given the importance of the fat-liver axis in the pathogenesis of obesity-associated dysmetabolism, we next assessed if the rapid near-normalization of glucose handling, insulin resistance and liver changes were also apparent at the adipose tissue level. We focused on adipose tissue insulin signaling, inflammation as well as MAP kinase stress signaling and ATM lipid content, all of which were implicated in the pathogenesis of obesityrelated whole-body and liver metabolic dysfunction. As seen in the liver (Fig. 2I), 10-weeks HFF resulted in impaired insulin-stimulated phosphorylation of key insulin signaling kinases in the adipose tissue, and this impairment was not improved when mice were switched to $\mathrm{NC}$ in the last 2 weeks (Fig. 3A and B). Histologically, compared to NC, adipose tissue of HFF mice exhibited significant adipocyte hypertrophy (Fig. 3C), which was still evident with only minor decrease in estimated mediumsized cells in $\mathrm{HFF} \rightarrow \mathrm{NC}$ mice (Fig. 3D). In addition, multiple typical crown-like structures in the HFF mice' adipose tissue seemed similarly abundant in the $\mathrm{HFF} \rightarrow \mathrm{NC}$ mice (Fig. 3C). Consistently, analysis of the stromal-vascular cell fraction of adipose tissue (obtained after collagenase digestion) by FACS revealed that the number of CD45+ leucocytes was increased in the HFF compared to the NC mice and remained similarly increased even after 2 weeks of dietary reversal (Fig. 3E). ATMs were identified from the CD45+ cell fraction by being double-positive for CD11b and F4/80 (Fig. 3F). Here, too, a similar increase was observed in the HFF and the $\mathrm{HFF} \rightarrow \mathrm{NC}$ groups compared to that in the NC control mice. This was further supported by whole adipose tissue mRNA content of Emr-1 (F4/80), which was markedly elevated in both HFF and HFF $\rightarrow$ NC compared to NC control (Fig. 3F).

To further estimate the impact of 2-week dietary reversal on adipose tissue inflammation, we assessed the mRNA levels of ATM M1/M2 polarization markers. Whole adipose tissue Tnfa levels were elevated 3.8- to 4.2-fold in both the HFF and HFF $\rightarrow$ NC mice compared to those in NC (Fig. 3G). The classical M1 polarization (and dendritic cell) marker CD11c was elevated 30-fold in HFF over NC and remained similarly elevated in the $\mathrm{HFF} \rightarrow \mathrm{NC}$ mice. Correspondingly, the ATM M2 polarization markers, Cd163 and Mgl2, were attenuated by HFF, and were only slightly, and not significantly, reversed by the 2-week dietary reversal (Fig. 3G). Thus, obesity-related adipose tissue inflammation, at least as evidenced by adipose tissue ATM infiltration and polarization state, was not reversed by the 2-week dietary switch.

Lipid-laden ATMs, or adipose tissue foam cells, have been associated with metabolic dysfunction in obesity (Shapiro et al. 2013). Furthermore, they were demonstrated to induce adipose tissue insulin resistance (Shapiro et al. 2013). To determine if ATM lipid content was affected by the 2-week dietary switch, we utilized the neutral lipid fluorescent dye BODIPY (Fig. 3H). HFF markedly increased BODIPY mean fluorescence intensity in ATM compared to that in NC. HFF $\rightarrow$ NC mice exhibited a $\sim 45 \%$ lower ATM lipid content than HFF. This finding suggests that despite seemingly maintained adipose tissue inflammation and macrophage number and polarization state, ATM lipid content, a signature of their lipid mishandling in obesity that potentially contributes to adipose tissue dysfunction, was significantly reversed.

An activated adipose tissue MAP kinase signaling cascade in human adipose tissue, consisting of the MAP3K ASK1 (MAP3K5), MKK4,3 and 6 and p38 MAP kinase and JNK, was shown to link obesity with wholebody insulin resistance (Rudich et al. 2007). Consistently, HFF induced increased activation (dual-phosphorylation) of p38 MAP kinase and JNK and their upstream kinase MKK4 (Fig. 3I). These changes were reversed in the $\mathrm{HFF} \rightarrow \mathrm{NC}$ group. Collectively, insulin responsiveness and common indicators of adipose tissue inflammation were not revered in $\mathrm{HFF} \rightarrow \mathrm{NC}$. Nevertheless, increased ATM lipid content and adipose tissue MAP kinase activation were significantly decreased. These two adipose tissue parameters demonstrate rapidly-reversible obesityrelated features of adipose tissue, which associate with the improved whole-body metabolism during obesity reversal.

To challenge the hypothesis that auto-paracrine and/ or endocrine mechanisms might contribute to the early metabolic improvement during obesity reversal, we screened for potential changes in secreted products from adipose tissue of $\mathrm{HFF} \rightarrow \mathrm{NC}$ vs HFF mice. Adipose tissueconditioned media were prepared using a fixed tissue mass/ volume ratio (100 mg tissue per $1 \mathrm{~mL}$ media), and secreted products from this tissue were analyzed. The concentration of free fatty acids (FFA) was not different between media of adipose tissue of HFF vs $\mathrm{HFF} \rightarrow \mathrm{NC}$ mice (Fig. 4A). Yet, when considering the adipose tissue weight, total delivery of FFA from the epididymal fat pad was increased in $\mathrm{HFF}$ and was markedly decreased in $\mathrm{HFF} \rightarrow \mathrm{NC}$ (Fig. 4B), demonstrating that the dysregulated basal lipolytic activity of this fat depot in obesity was in fact reversed by dietary reversal. Next, conditioned media of adipose tissue explants

Published by Bioscientifica Ltd 
B
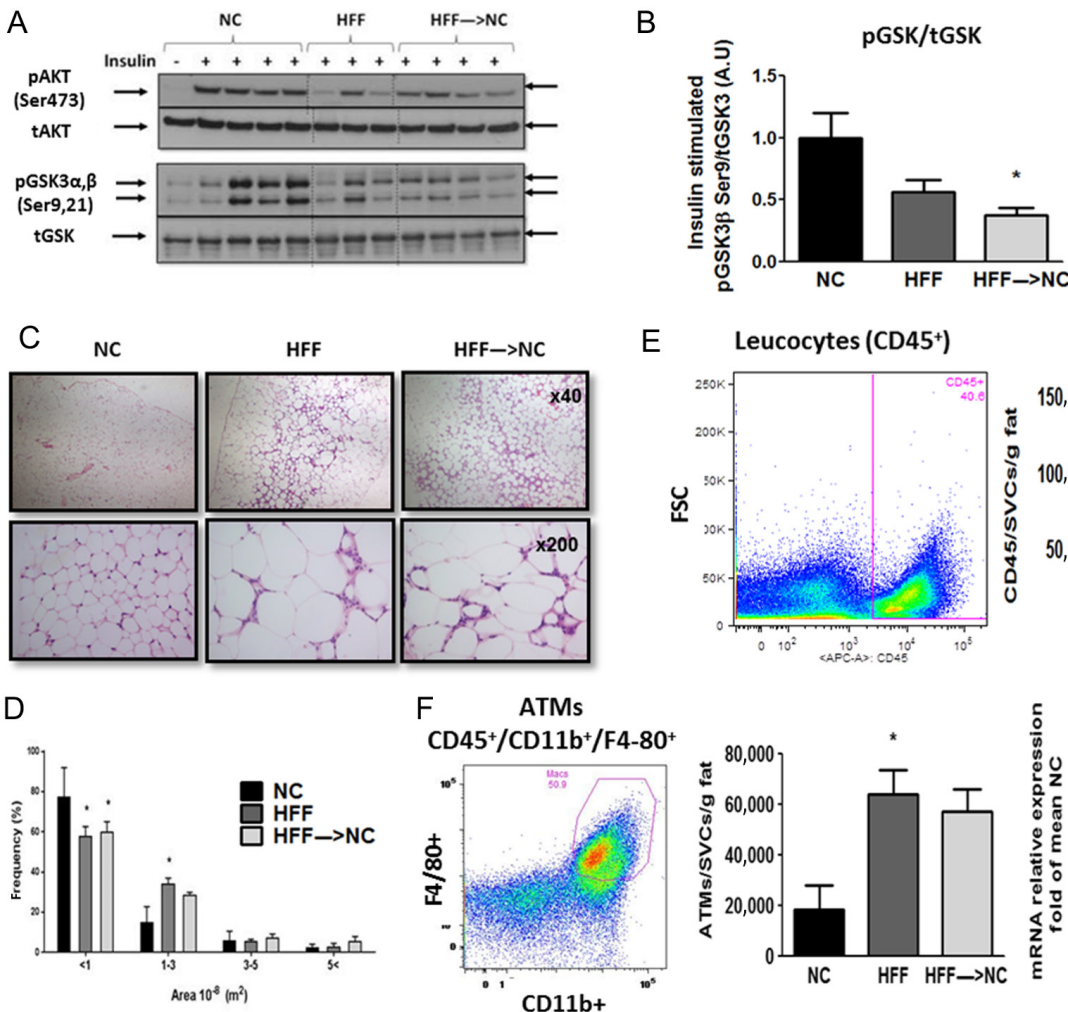

E
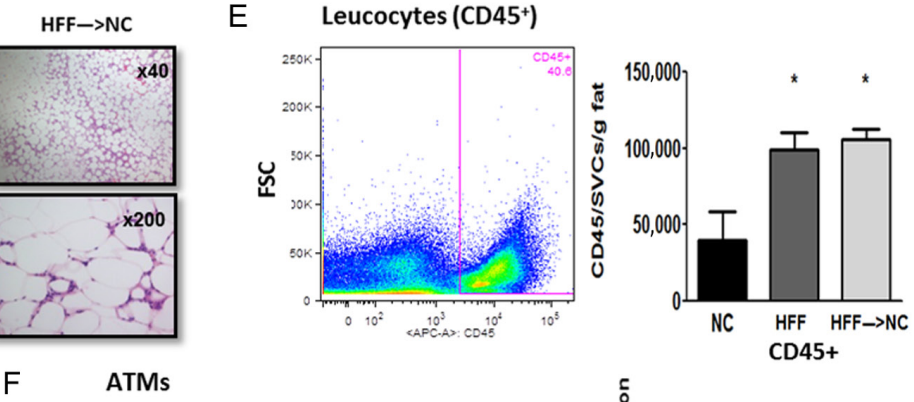

F $\frac{\text { ATMs }}{\mathrm{CD}^{+} 5^{+} / \mathrm{CD}_{11 b^{+} / \mathrm{F}-80^{+}}}$
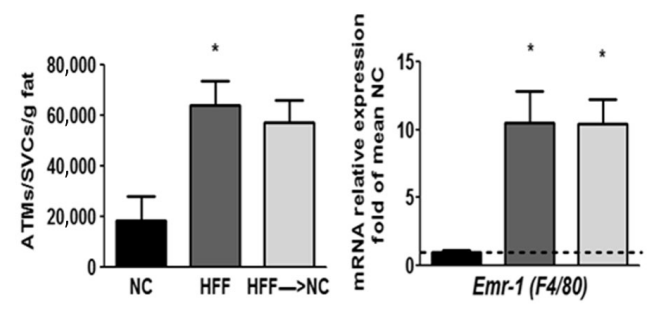

G
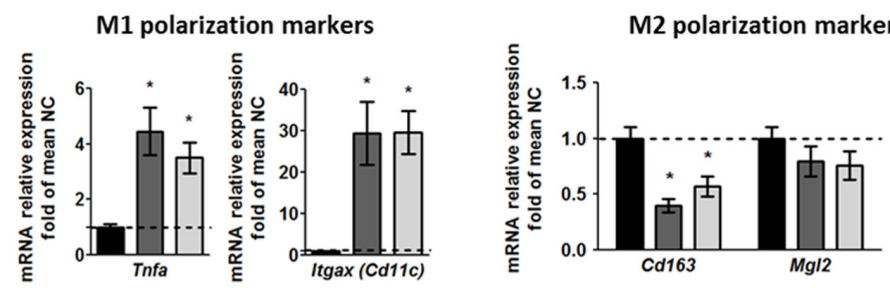

$\mathrm{H}$
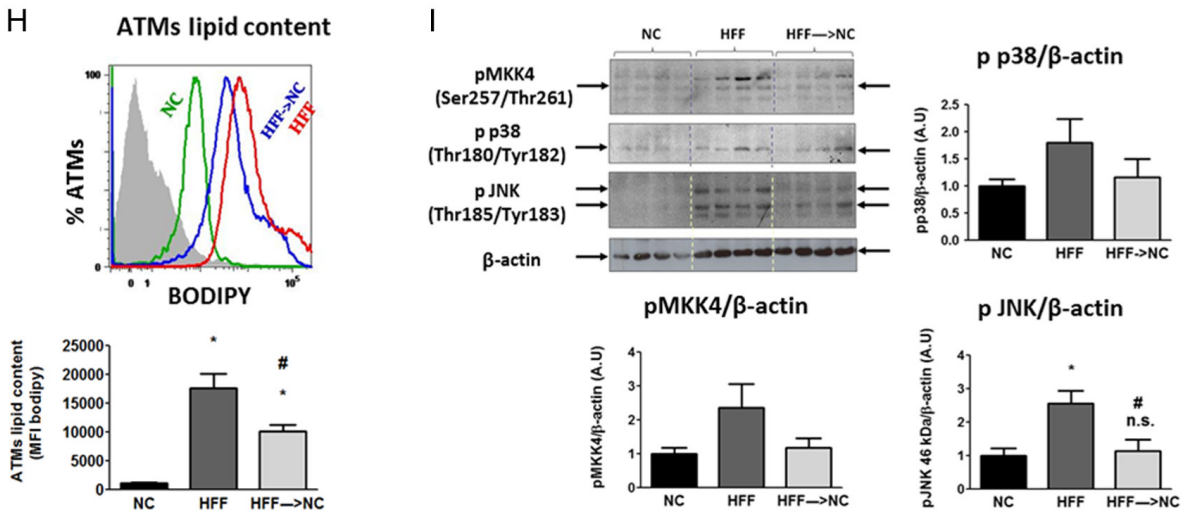

Figure 3

Adipose tissue adaptation to 2 weeks obesity reversal. (A and B) Representative blots and densitometry ( $n=7-12 /$ group from 2 to 3 independent experiments) of insulin signaling proteins in epididymal adipose tissue of mice treated as detailed in Fig. $2 \mathrm{l}$ and J. (C and D) Representative adipose tissue histological sections stained with H\&E, and estimated size distribution. Flow Cytometry analyses of adipose tissue stromal-vascular cell fraction: Leucocytes were identified as CD45+ (E), adipose tissue macrophages (ATMs) as CD11 b+F4/80+ $(F)$, and ATM lipid content was assessed using the neutral lipid fluorescent dye BODIPY (H). Results are mean \pm S.E.M. of mice from 2 independent experiments. Quantitative real-time PCR analysis in epididymal adipose tissue: Emr-1 (F4/80) as a marker for macrophages (F), Tnfa was used as a classical pro-inflammatory cytokine and with Itgax (Cd11c) as M1 markers, and Cd163 and Mg/2 as markers of alternatively activated, M2 macrophages (G). Values are the $\triangle \Delta C T$ adjusted to Rp/p0 and Hprt, and are represented as fold of mean value of the NC group ( $n=14-17 / g r o u p$ from 5 independent experiments). (I) Representative blots and densitometry of adipose tissue stress signaling proteins. Densitometry are mean \pm S.E.M. of $n=11$-16/group from 3 to 4 independent experiments, with the mean value of the NC group defined as a value of 1. n.s. or $* P<0.05$ vs NC, ${ }^{*} P<0.05$ vs HFF. A full colour version of this figure is available at $h$ ttp://dx.doi.org/10.1530/JOE-17-0007. 
A

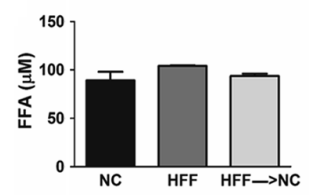

B

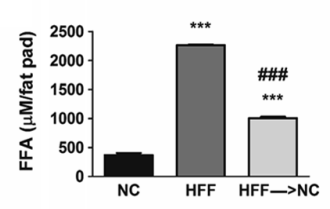

C

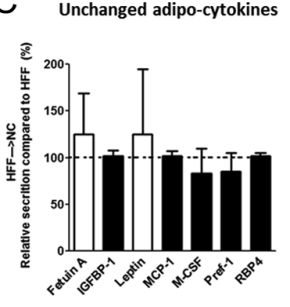

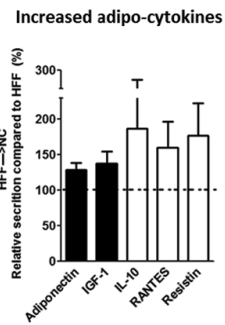

Decreased adipo-cytokines

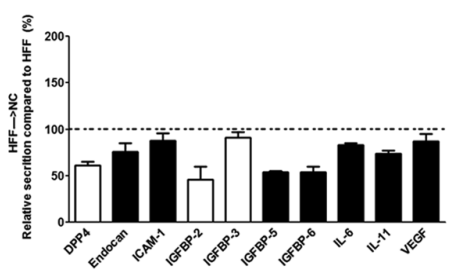

\section{Figure 4}

Changes in adipocytokine secretion from adipose tissue upon dietary switch. (A) FFA concentrations in CM of adipose tissue (100 mg tissue/mL medium). (B) Total FFA production by epididymal fat pads. (C) Adipocytokine array was used to screen for changes induced by dietary switch in the secretion of adipocytokines by cultured adipose tissue fragments. The levels of each adipocytokine were quantified by densitometry and expressed as fold of HFF for each adipokine. The detected factors were divided to those which qualitatively changed similarly (black bars) or differently (white bars) to their change induced in HFF adipose tissue by incubation with p38MAPK + JNK inhibitors (results of this analysis is presented in Supplementary Fig. 1). Results are mean \pm S.D. of 2-3 independent experiments.

was screened by an adipocytokine array, revealing highly diverse response of these secreted products in adipose tissue of $\mathrm{HFF} \rightarrow \mathrm{NC}$ compared to HFF (Fig. 4C). Among others, concentrations of leptin and RBP4 were not different in $\mathrm{HFF} \rightarrow \mathrm{NC}$ compared to HFF, adiponectin and IL-10, but also resistin - were increased, and IL-6 and DPP4 decreased (Fig. 4C). To estimate if the decrease in activation of p38 MAPK and JNK (Fig. 3I) could account for these changes in the secretion of adipokines, we compared these changes to those induced by incubating adipose tissue from HFF mice with inhibitors of these two kinases (Supplementary Fig. 1). Qualitatively, 13 of 22 proteins (59\%) exhibited similar changes (marked by the black bars, Fig. 4C). Most notable were the increase in adiponectin and decreases in Endocan, ICAM-1, IGFBP5 and 6, IL-6, 11, Pref-1 (DLK1) and VEGF.

Finally, we wished to assess the overall impact of the observed changes in secretory profile induced by dietary reversal on adipose tissue's endocrine communication (with liver-derived cells) and auto-paracrine communication (i.e., with macrophages). Hepatoma cells co-cultured with adipose tissue of HFF exhibited impaired insulin responsiveness compared to $\mathrm{NC}$, and this impairment was also apparent upon exposure to adipose tissue from $\mathrm{HFF} \rightarrow \mathrm{NC}$ adipose tissue (Fig. 5A). This largely recapitulated insulin signaling in vivo (Fig. 2I), which was not improved in the $\mathrm{HFF} \rightarrow \mathrm{NC}$ group compared to HFF and remained lower than that in NC. For assessing the potential impact of adipose tissue on lipid accumulation by liver-derived cells, conditioned media of HFF adipose tissue was used. Higher lipid droplet formation was observed in liver-derived cells incubated with condition media of HFF adipose tissue compared to that of NC, an effect that was significantly less pronounced (though not normalized) in cells exposed to $\mathrm{HFF} \rightarrow \mathrm{NC}$ media (Fig. 5B). Addressing auto-paracrine actions was performed by assessing macrophage lipid accumulation as ATM in $\mathrm{HFF} \rightarrow \mathrm{NC}$ mice had lower lipid content than HFF (Fig. 3H). RAW264.7 macrophages incubated with conditioned media of HFF adipose tissue had higher lipid content than those exposed to NC adipose tissue media, and this was not apparent with conditioned media from the $\mathrm{HFF} \rightarrow \mathrm{NC}$ mice (Fig. 5C). This finding supports a role for improved paracrine communication within adipose tissue in mice early after dietary reversal of obesity.

\section{Discussion}

The results of this study demonstrate that despite continued macrophage infiltration and M1 polarization in adipose tissue, functionally, adipose tissue's autoparacrine and endocrine communication contributes to normalization of lipid handling by macrophages and liver-derived cells early upon dietary reversal of obesity: lipid accumulation in macrophages was fully normalized when incubated with $\mathrm{CM}$ from $\mathrm{HFF} \rightarrow \mathrm{NC}$ mice, and partial reversal of the enhanced lipid accumulation by liver-derived cells was also observed. Secretion of selected adipocytokines, including increase in adiponectin and IL-10 and decrease in IL- 6 and RBP4 by adipose tissue explants were associated with this effect, which could be partially recapitulated by incubating adipose tissue from HFF mice with MAP kinase inhibitors. These results from the ex vivo systems nicely reflected the early response to dietary reversal observed in vivo in obese mice: Like in the in vitro system, in the $\mathrm{HFF} \rightarrow \mathrm{NC}$ mice, liver insulin signaling after administering an insulin bolus (i.e., hepatic insulin responsiveness) was also not improved, consistent with previous studies (Jung et al. 2013). Nevertheless, in adipose tissue, ATM lipid content was decreased, suggesting a http://joe.endocrinology-journals.org DOI: 10.1530/JOE-17-0007
(C) 2017 The authors Printed in Great Britain
Published by Bioscientifica Ltd 
Co-cultured Hepa-1c and AT fat pads
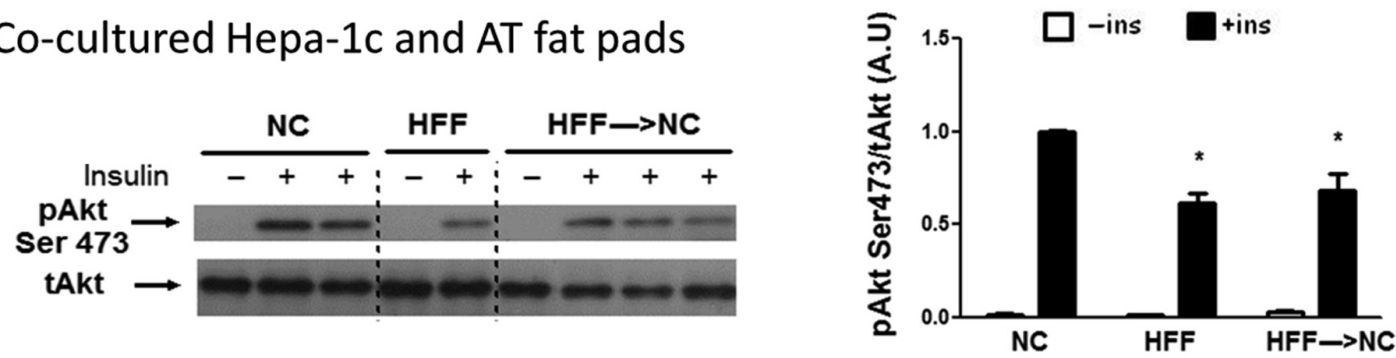

B Hepa-1c
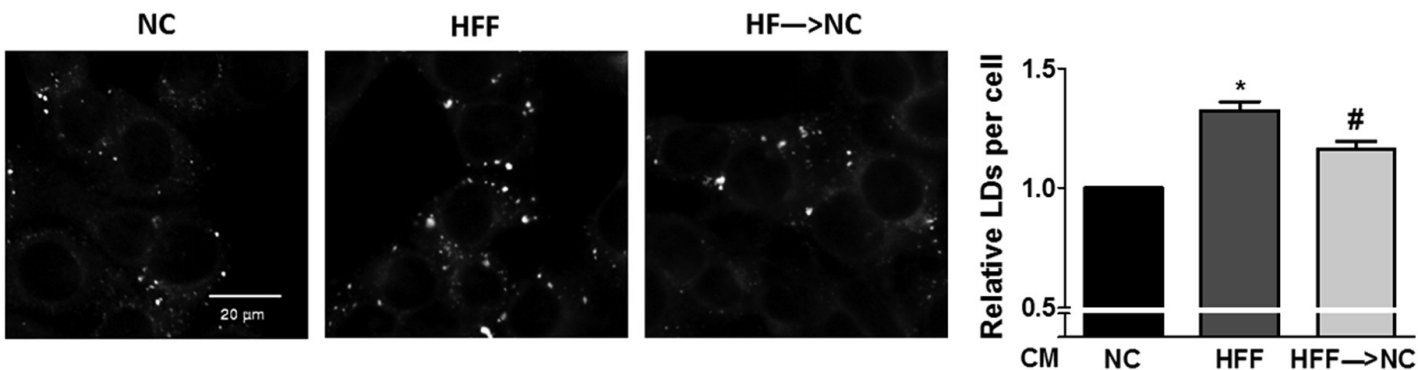

\section{RAW264.7}
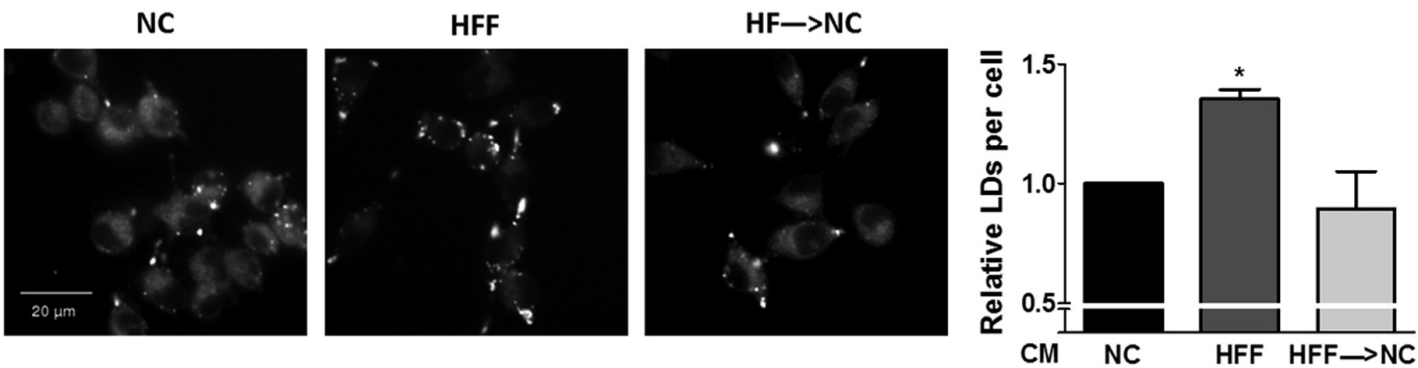

\section{Figure 5}

Functional reversal of increased liver cell and macrophage lipid storage by adipose tissue conditioned medium. (A) Insulin-stimulated Akt phosphorylation in Hepa-1c hepatoma cells exposed to conditioned media of adipose tissue from NC, HFF, and HFF $\rightarrow$ NC mice. Shown is a representative blot and densitometry analyses normalized to the signal in insulin stimulated cells pre-treated with conditioned media of NC mice. N=4-20 individual wells from 2 independent experiments, ${ }^{*} P<0.05$ vs NC. Hepa-1c hepatoma cells (B) and RAW264.7 macrophages (C) were treated with adipose tissue conditioned media (AT-CM) for 6 h. Lipid droplets (LDs) were stained with BODIPY 493/503 neutral lipid dye and imaged by Operetta high content imaging system. Graphs represent the relative number of LDs per cell, compared to NC treated cells. The results are expressed as mean \pm s.E.M. of five (Hepa-1c) or four (RAW264.7) independent experiments, each preformed in triplicates. * or ${ }^{P}<0.05$ compared to NC or HFF, respectively.

reversal of the contribution of adipose tissue foam cells to dysmetabolism. Moreover, hepatic steatosis and the accompanying increased whole-body glucose production were significantly/fully normalized. Jointly, our results highlight a measurable contribution of adipose tissue to the rapid metabolic normalization upon dietary reversal of obesity via auto-paracrine and endocrine mechanisms. Notably, greater changes in adipose tissue inflammation may further contribute to metabolic normalization after more extended periods of obesity reversal (Kosteli et al. 2010), beyond the single time point studied herein.

A central role is now assigned to adipose tissue in the pathogenesis of obesity-associated metabolic dysfunction, with particular emphasis on the fat-liver axis (i.e., in hepatic steatosis, insulin resistance and glucose overproduction) (Item \& Konrad 2012, Kloting \& Bluher 2014). Thus, the robust reversal of the hepatic steatosis and glucose overproduction in the $\mathrm{HFF} \rightarrow \mathrm{NC}$ group is somewhat surprising given the relatively minor reversal of adipose tissue changes after 2 weeks, including many common markers of adipose tissue inflammation. This may suggest that despite the central role of adipose tissue in obesity development, other tissues such as muscle (not assessed herein), or the liver, predominate early in the reversal phase. Indeed, in the rapid glycemic improvement seen after bariatric surgery, incretins and bile acids have http://joe.endocrinology-journals.org DOI: 10.1530/JOE-17-0007
(C) 2017 The authors Printed in Great Britain
Published by Bioscientifica Ltd 
been raised as potential major mediators (Laferrere 2011, Noel et al. 2016). These highlight a gut-liver axis that may predominate over fat-liver communication, and indeed, liver-autonomous mechanisms (or at least mechanisms unrelated to adipose tissue) are likely to play a role. Yet, using ex vivo systems that can isolate specific interorgan/cell-type interactions from the multiple changes occurring in vivo, our data suggest that functionally there is a potential contribution of adipose tissue, via auto/ paracrine and endocrine mechanisms. This could engage various mediators, including FFA, protein or steroidal hormones and other lipid mediators, secreted directly to the extracellular environment and/or, as recently proposed, via exosomes (Lazar et al. 2016). The total delivery of FFA to the liver (i.e., when considering both the secretion and the mass of the adipose tissue) is markedly decreased in $\mathrm{HFF} \rightarrow \mathrm{NC}$ compared to HFF, and thus, likely plays a role in decreasing lipid accumulation in both ATM and the liver. Yet, the ex vivo system utilized herein demonstrated effects beyond FFA as the concentration of either glycerol or FFA in the media that was generated by a wt/vol ratio were not different, likely because $100 \mathrm{mg}$ of HFF tissue includes a smaller number of adipocytes than the same mass of $\mathrm{NC}$ or $\mathrm{HFF} \rightarrow \mathrm{NC}$ adipose tissue.

Screening for secreted adipocytokines (i.e., proteins), our data suggest that some factors are not reversed in the $\mathrm{HFF} \rightarrow \mathrm{NC}$ group, whereas others do change, including increase in adiponectin and IL-10 and decreases in adipose tissue secretion of DPP4 and IL-6. Increased adiponectin has been shown to mediate improved fatliver communication when adipose tissue of HFF mice was treated with a lysosomal/autophagosomal inhibitor (Slutsky et al. 2016), though such improved insulin signaling was not observed here. Nevertheless, adiponectin is causally linked to obesity-related steatosis by knockout and transgenic models (Kim et al. 2007, Liu et al. 2012), the latter demonstrating that overexpression of adiponectin can prevent liver steatosis despite marked obesity. A very recent study in mice suggested that increased adiponectin and expression of its receptors in the liver mediate the advantageous combination of caloric restriction (dietary switch) and exercise, over each intervention alone (Cho et al. 2016). Decreased circulating IL-10 was recently shown to associate with the severity of NAFLD (Paredes-Turrubiarte et al. 2016), and treatment with a PEGylated IL-10 was shown to decrease liver lipid content, possibly acting on Kupffer cells (Chan et al. 2016). Interestingly, adiponectin suppresses macrophage lipid accumulation (Tian et al. 2012, Wang et al. 2013) and increases IL-10 production (Park et al. 2007). This provides a putative intra-adipose tissue, adipocyte-macrophage paracrine communication, leading to beneficial adiposeliver endocrine communication, which ultimately supports the rapid metabolic response to dietary switch. Adipose tissue release of DPP4 was shown to strongly associate with visceral fat and clinical characteristics of dysmetabolic obesity (Sell et al. 2013), and DPP4 inhibitors seem to prevent and/or improve liver steatosis (Rohrborn et al. 2015). Although local production of DPP4 in the liver may be the most biologically relevant source for NAFLD (Miyazaki et al. 2012), decreased delivery of adipose-derived DPP4 to the liver could also contribute, possibly interacting with higher incretin delivery during obesity reversal. Finally, IL-6 is likely the cytokine most implicated in obesity-related NAFLD development and progression. In particular, in obesity, adipocyte JNK activation was tied in mice to NAFLD by regulating IL- 6 as an endocrine mediator in the fat-liver axis (Sabio et al. 2008). Indeed, comparing changes in the adipocytokine profile of $\mathrm{HFF} \rightarrow \mathrm{NC}$ vs HFF to the effect of combined pharmacological inhibition of adipose tissue JNK and p38 MAP kinase suggests the following pathway: obesity reversal rapidly normalizes p38 MAPK and JNK hyperactivation, resulting in changes in adipocytokine secretion from adipose tissue (including increases in adiponectin and IL-10 and decreased secretion of DPP4 and IL-6). These contribute to the improvement in hepatic steatosis and dysglycemia. Indeed, the potential clinical significance of obesity-associated hyperactivation of an ASK1-MKK4-p38/JNK MAP kinase signaling cascade in visceral fat was previously reported (Bashan et al. 2007, Bluher et al. 2009).

The auto-paracrine impact of obesity reversal within adipose tissue could be demonstrated by the finding that $\mathrm{CM}$ from $\mathrm{HFF} \rightarrow \mathrm{NC}$ adipose tissue completely normalizes the enhanced macrophage lipid accumulation induced by $\mathrm{CM}$ from HFF mice. In vivo, although adipose tissue leucocytes and macrophages, as well as their polarization markers, were not significantly reversed within 2 weeks of dietary switch, ATM lipid content decreased by $\sim 45 \%$. Adipose tissue lipid-laden foam cells associate in humans with insulin-resistant obesity and could be functionally tied to adipose tissue insulin resistance (Shapiro et al. 2013). In addition, the degree of adipose tissue macrophage infiltration in obesity was shown to associate with NAFLD and its severity (Tordjman et al. 2009). Our data might suggest a particular causal contribution of ATM lipid content and adipose tissue foam cells to NAFLD,
Published by Bioscientifica Ltd. 
possibly beyond classical inflammatory activation of the ATM, consistent with previous reports (Xu et al. 2013, Kratz et al. 2014). Alternatively, adipose tissue immune cells other than macrophages (like various subclasses of lymphocytes) may contribute to early reversal of obesityinduced dysregulated adipose tissue endocrine function (Chatzigeorgiou et al. 2012).

In summary, this study highlights a previously unrecognized functional contribution of adipose tissue to the metabolic normalization induced by 2 weeks of dietary reversal of obesity. Our results are consistent with the notion that early in obesity reversal, rapid normalization of dysglycemia is matched by a robust improvement in hepatic steatosis and metabolism (though not insulin signaling responsiveness) (Jung et al. 2013, Cho et al. 2016). These precede normalization of major inflammatory changes induced by obesity in adipose tissue. Nevertheless, adipose tissue's auto-paracrine and endocrine regulation of lipid handling by macrophages and liver cells is normalized, contributing to the recovery from the metabolic consequences of obesity.

\section{Supplementary data}

This is linked to the online version of the paper at http://dx.doi.org/10.1530/ JOE-17-0007.

\section{Declaration of interest}

The authors declare that there is no conflict of interest that could be perceived as prejudicing the impartiality of the research reported.

\section{Funding}

This study was supported in part by grants from the Israel Science Foundation (ISF 874/15) and by the Deutsche Forschungsgemeinschaft (DFG) (SFB 1052/1: Obesity mechanisms (project B2)). M V and S B were supported by the National Institute of Biotechnology in the Negev (NIBN), Ben-Gurion University, Beer-Sheva, Israel. A R is Chair of the Fraida Foundation in Diabetes Research.

\section{Authors' contribution statement}

M V conducted the study, performed data collection and analysis and data presentation, participated in manuscript writing; S B conducted the study, performed data collection and analysis and data interpretation, participated in manuscript writing; $\mathrm{Y} \mathrm{H}$ performed data analysis and interpretation; $\mathrm{T}$ P participated in data collection and analysis; T T participated in data collection; N S participated in data collection; O N participated in data collection; H S participated in data collection and analysis; A S participated in data collection; A P participated in study design and data analysis; N B participated in data analysis and interpretation; A R participated in study design, data analysis and interpretation and wrote the manuscript.

\section{References}

Bashan N, Dorfman K, Tarnovscki T, Harman-Boehm I, Liberty IF, Bluher M, Ovadia S, Maymon-Zilberstein T, Potashnik R, Stumvoll M, et al. 2007 Mitogen-activated protein kinases, inhibitory-kappaB kinase, and insulin signaling in human omental versus subcutaneous adipose tissue in obesity. Endocrinology 148 2955-2962. (doi:10.1210/en.2006-1369)

Bluher M, Bashan N, Shai I, Harman-Boehm I, Tarnovscki T, Avinaoch E, Stumvoll M, Dietrich A, Kloting N \& Rudich A 2009 Activated Ask1-MKK4-p38MAPK/JNK stress signaling pathway in human omental fat tissue may link macrophage infiltration to whole-body Insulin sensitivity. Journal of Clinical Endocrinology and Metabolism 94 2507-2515. (doi:10.1210/jc.2009-0002)

Bradley D, Magkos F \& Klein S 2012 Effects of bariatric surgery on glucose homeostasis and type 2 diabetes. Gastroenterology 143 897-912. (doi:10.1053/j.gastro.2012.07.114)

Chan IH, Van Hoof D, Abramova M, Bilardello M, Mar E, Jorgensen B, McCauley S, Bal H, Oft M, Van Vlasselaer P, et al. 2016 PEGylated IL-10 activates kupffer cells to control hypercholesterolemia. PLoS ONE 11 e0156229. (doi:10.1371/journal.pone.0156229)

Chatzigeorgiou A, Karalis KP, Bornstein SR \& Chavakis T 2012 Lymphocytes in obesity-related adipose tissue inflammation. Diabetologia 55 2583-2592. (doi:10.1007/s00125-012-2607-0)

Cho YM 2014 A gut feeling to cure diabetes: potential mechanisms of diabetes remission after bariatric surgery. Diabetes and Metabolism Journal 38 406-415. (doi:10.4093/dmj.2014.38.6.406)

Cho J, Koh Y, Han J, Kim D, Kim T \& Kang H 2016 Adiponectin mediates the additive effects of combining daily exercise with caloric restriction for treatment of non-alcoholic fatty liver. International Journal of Obesity 40 1760-1767. (doi:10.1038/ijo.2016.104)

Elgazar-Carmon V, Rudich A, Hadad N \& Levy R 2008 Neutrophils transiently infiltrate intra-abdominal fat early in the course of highfat feeding. Journal of Lipid Research 49 1894-1903. (doi:10.1194/jlr. M800132-JLR200)

Fabbrini E, Magkos F, Mohammed BS, Pietka T, Abumrad NA, Patterson BW, Okunade A \& Klein S 2009 Intrahepatic fat, not visceral fat, is linked with metabolic complications of obesity. PNAS $\mathbf{1 0 6}$ 15430-15435. (doi:10.1073/pnas.0904944106)

Hadad N, Burgazliev O, Elgazar-Carmon V, Solomonov Y, Wueest S, Item F, Konrad D, Rudich A \& Levy R 2013 Induction of cytosolic phospholipase a2alpha is required for adipose neutrophil infiltration and hepatic insulin resistance early in the course of high-fat feeding. Diabetes 62 3053-3063. (doi:10.2337/db12-1300)

Harman-Boehm I, Bluher M, Redel H, Sion-Vardy N, Ovadia S, Avinoach E, Shai I, Kloting N, Stumvoll M, Bashan N, et al. 2007 Macrophage infiltration into omental versus subcutaneous fat across different populations: effect of regional adiposity and the comorbidities of obesity. Journal of Clinical Endocrinology and Metabolism 92 2240-2247. (doi:10.1210/jc.2006-1811)

Item F \& Konrad D 2012 Visceral fat and metabolic inflammation: the portal theory revisited. Obesity Reviews 13 (Supplement 2) 30-39. (doi:10.1111/j.1467-789X.2012.01035.x)

Jung DY, Ko HJ, Lichtman EI, Lee E, Lawton E, Ong H, Yu K, Azuma Y, Friedline RH, Lee KW, et al. 2013 Short-term weight loss attenuates local tissue inflammation and improves insulin sensitivity without affecting adipose inflammation in obese mice. American Journal of Physiology: Endocrinology and Metabolism 304 E964-E976. (doi:10.1152/ajpendo.00462.2012)

Kim JY, van de Wall E, Laplante M, Azzara A, Trujillo ME, Hofmann SM, Schraw T, Durand JL, Li H, Li G, et al. 2007 Obesity-associated improvements in metabolic profile through expansion of adipose tissue. Journal of Clinical Investigation 117 2621-2637. (doi:10.1172/ JCI31021)

Kloting N \& Bluher M 2014 Adipocyte dysfunction, inflammation and metabolic syndrome. Reviews in Endocrine and Metabolic Disorders 15 277-287. (doi:10.1007/s11154-014-9301-0) http://joe.endocrinology-journals.org

DOI: $10.1530 / \mathrm{JOE}-17-0007$ (c) 2017 The authors Printed in Great Britain
Published by Bioscientifica Ltd 
Kloting N, Fasshauer M, Dietrich A, Kovacs P, Schon MR, Kern M, Stumvoll M \& Bluher M 2010 Insulin-sensitive obesity. American Journal of Physiology: Endocrinology and Metabolism 299 E506-E515. (doi:10.1152/ajpcell.00006.2010)

Kosteli A, Sugaru E, Haemmerle G, Martin JF, Lei J, Zechner R \& Ferrante AW Jr 2010 Weight loss and lipolysis promote a dynamic immune response in murine adipose tissue. Journal of Clinical Investigation 120 3466-3479. (doi:10.1172/JCI42845)

Kratz M, Coats Brittney R, Hisert Katherine B, Hagman D, Mutskov V, Peris E, Schoenfelt Kelly Q, Kuzma Jessica N, Larson I, Billing Peter S, et al. 2014 Metabolic dysfunction drives a mechanistically distinct proinflammatory phenotype in adipose tissue macrophages. Cell Metabolism 20 614-625. (doi:10.1016/j.cmet.2014.08.010)

Laferrere B 2011 Diabetes remission after bariatric surgery: is it just the incretins? International Journal of Obesity 35 (Supplement 3) S22-S25. (doi:10.1038/ijo.2011.143)

Lazar I, Clement E, Dauvillier S, Milhas D, Ducoux-Petit M, LeGonidec S, Moro C, Soldan V, Dalle S, Balor S, et al. 2016 Adipocyte exosomes promote melanoma aggressiveness through fatty acid oxidation: a novel mechanism linking obesity and cancer. Cancer Research $\mathbf{7 6}$ 4051-4057. (doi:10.1158/0008-5472.CAN-16-0651)

Liu Q, Yuan B, Lo KA, Patterson HC, Sun Y \& Lodish HF 2012 Adiponectin regulates expression of hepatic genes critical for glucose and lipid metabolism. PNAS 109 14568-14573. (doi:10.1073/ pnas.1211611109)

Miyazaki M, Kato M, Tanaka K, Tanaka M, Kohjima M, Nakamura K, Enjoji M, Nakamuta M, Kotoh K \& Takayanagi R 2012 Increased hepatic expression of dipeptidyl peptidase-4 in non-alcoholic fatty liver disease and its association with insulin resistance and glucose metabolism. Molecular Medicine Reports 5 729-733. (doi:10.3892/mmr.2011.707)

Noel OF, Still CD, Argyropoulos G, Edwards M \& Gerhard GS 2016 Bile acids, FXR, and metabolic effects of bariatric surgery. Journal of Obesity 2016 4390254. (doi:10.1155/2016/4390254)

Nov O, Shapiro H, Ovadia H, Tarnovscki T, Dvir I, Shemesh E, Kovsan J, Shelef I, Carmi Y, Voronov E, et al. 2013 Interleukin-1beta regulates fat-liver crosstalk in obesity by auto-paracrine modulation of adipose tissue inflammation and expandability. PLOS ONE 8 e53626. (doi:10.1371/journal.pone.0053626)

Paredes-Turrubiarte G, Gonzalez-Chavez A, Perez-Tamayo R, SalazarVazquez BY, Hernandez VS, Garibay-Nieto N, Fragoso JM \& Escobedo G 2016 Severity of non-alcoholic fatty liver disease is associated with high systemic levels of tumor necrosis factor alpha and low serum interleukin 10 in morbidly obese patients. Clinical and Experimental Medicine 16 193-202. (doi:10.1007/s10238-0150347-4)

Park PH, McMullen MR, Huang H, Thakur V \& Nagy LE 2007 Short-term treatment of RAW264.7 macrophages with adiponectin increases tumor necrosis factor-alpha (TNF-alpha) expression via ERK1/2 activation and Egr-1 expression: role of TNF-alpha in adiponectinstimulated interleukin-10 production. Journal of Biological Chemistry 282 21695-21703. (doi:10.1074/jbc.M701419200)

Rohrborn D, Wronkowitz N \& Eckel J 2015 DPP4 in diabetes. Frontiers in Immunology 6 386. (doi:10.3389/fimmu.2015.00386)

Rudich A, Kanety H \& Bashan N 2007 Adipose stress-sensing kinases: linking obesity to malfunction. Trends in Endocrinology and Metabolism 18 291-299. (doi:10.1016/j.tem.2007.08.006)
Rytka JM, Wueest S, Schoenle EJ \& Konrad D 2011 The portal theory supported by venous drainage-selective fat transplantation. Diabetes 60 56-63. (doi:10.2337/db10-0697)

Sabio G, Das M, Mora A, Zhang Z, Jun JY, Ko HJ, Barrett T, Kim JK \& Davis RJ 2008 A stress signaling pathway in adipose tissue regulates hepatic insulin resistance. Science 322 1539-1543. (doi:10.1126/science.1160794)

Sell H, Bluher M, Kloting N, Schlich R, Willems M, Ruppe F, Knoefel WT, Dietrich A, Fielding BA, Arner P, et al. 2013 Adipose dipeptidyl peptidase- 4 and obesity: correlation with insulin resistance and depot-specific release from adipose tissue in vivo and in vitro. Diabetes Care 36 4083-4090. (doi:10.2337/dc13-0496)

Shapiro H, Pecht T, Shaco-Levy R, Harman-Boehm I, Kirshtein B, Kuperman Y, Chen A, Bluher M, Shai I \& Rudich A 2013 Adipose tissue foam cells are present in human obesity. Journal of Clinical Endocrinology and Metabolism 98 1173-1181. (doi:10.1210/jc.2012-2745)

Slutsky N, Vatarescu M, Haim Y, Goldstein N, Kirshtein B, HarmanBoehm I, Gepner Y, Shai I, Bashan N, Bluher M, et al. 2016 Decreased adiponectin links elevated adipose tissue autophagy with adipocyte endocrine dysfunction in obesity. International Journal of Obesity $\mathbf{4 0}$ 912-920. (doi:10.1038/ijo.2016.5)

Talukdar S, Oh DY, Bandyopadhyay G, Li D, Xu J, McNelis J, Lu M, Li P, Yan Q, Zhu Y, et al. 2012 Neutrophils mediate insulin resistance in mice fed a high-fat diet through secreted elastase. Nature Medicine 18 1407-1412. (doi:10.1038/nm.2885)

Tian L, Luo N, Zhu X, Chung BH, Garvey WT \& Fu Y 2012 AdiponectinAdipoR1/2-APPL1 signaling axis suppresses human foam cell formation: differential ability of AdipoR1 and AdipoR2 to regulate inflammatory cytokine responses. Atherosclerosis $22166-75$. (doi:10.1016/j.atherosclerosis.2011.12.014)

Tordjman J, Poitou C, Hugol D, Bouillot JL, Basdevant A, Bedossa P, Guerre-Millo M \& Clement K 2009 Association between omental adipose tissue macrophages and liver histopathology in morbid obesity: influence of glycemic status. Journal of Hepatology $\mathbf{5 1}$ 354-362. (doi:10.1016/j.jhep.2009.02.031)

Varela JE 2011 Bariatric surgery: a cure for diabetes? Current Opinion in Clinical Nutrition and Metabolic Care 14 396-401. (doi:10.1097/ MCO.0b013e3283468e50)

Wang M, Wang D, Zhang Y, Wang X, Liu Y \& Xia M 2013 Adiponectin increases macrophages cholesterol efflux and suppresses foam cell formation in patients with type 2 diabetes mellitus. Atherosclerosis 229 62-70. (doi:10.1016/j.atherosclerosis.2013.01.017)

Wueest S, Rapold RA, Schumann DM, Rytka JM, Schildknecht A, Nov O, Chervonsky AV, Rudich A, Schoenle EJ, Donath MY, et al. 2010 Deletion of Fas in adipocytes relieves adipose tissue inflammation and hepatic manifestations of obesity in mice. Journal of Clinical Investigation 120 191-202. (doi:10.1172/JCI38388)

Xu X, Grijalva A, Skowronski A, van Eijk M, Serlie MJ \& Ferrante AW Jr2013 Obesity activates a program of lysosomal-dependent lipid metabolism in adipose tissue macrophages independently of classic activation. Cell Metabolism 18 816-830. (doi:10.1016/j. cmet.2013.11.001)

Zhang X, Xu A, Chung SK, Cresser JH, Sweeney G, Wong RL, Lin A \& Lam KS 2011 Selective inactivation of c-Jun NH2-terminal kinase in adipose tissue protects against diet-induced obesity and improves insulin sensitivity in both liver and skeletal muscle in mice. Diabetes 60 486-495. (doi:10.2337/db10-0650)

Received in final form 8 March 2017

Accepted 30 March 2017

Accepted Preprint published online 30 March 2017 http://joe.endocrinology-journals.org

DOI: $10.1530 / J O E-17-0007$ (c) 2017 The authors Printed in Great Britain
Published by Bioscientifica Ltd 